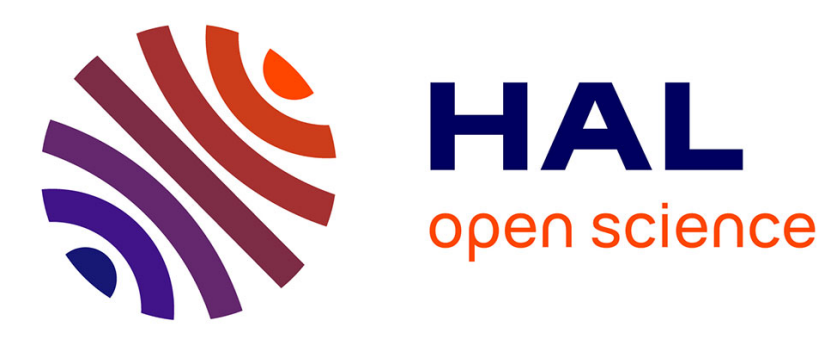

\title{
High-Purity Chromium Targets
}

\author{
A. Rudoy, Yu. Milman, N. Korzhova
}

\section{To cite this version:}

A. Rudoy, Yu. Milman, N. Korzhova. High-Purity Chromium Targets. Journal de Physique IV Proceedings, 1995, 05 (C7), pp.C7-149-C7-152. 10.1051/jp4:1995714 . jpa-00254007

\section{HAL Id: jpa-00254007 https://hal.science/jpa-00254007}

Submitted on 1 Jan 1995

HAL is a multi-disciplinary open access archive for the deposit and dissemination of scientific research documents, whether they are published or not. The documents may come from teaching and research institutions in France or abroad, or from public or private research centers.
L'archive ouverte pluridisciplinaire HAL, est destinée au dépôt et à la diffusion de documents scientifiques de niveau recherche, publiés ou non, émanant des établissements d'enseignement et de recherche français ou étrangers, des laboratoires publics ou privés. 


\title{
High-Purity Chromium Targets
}

\author{
A.P. Rudoy, Yu.V. Milman and N.P. Korzhova \\ Institute for Problems of Materials Science Ukrainian, Academy of Science, 3 Krgiganovsky str., \\ 252180 Kiev, Ukraine
}

\begin{abstract}
A procedure for producing large-scale chromium ingots by means of induction-arc melting was developed. From the high-purity, low-alloyed chromium ingots obtained, chromium targets were produced by of thermoplastic treatment techniques. The method of electron-beam evaporation of high-purity chromium was also used for production of targets.
\end{abstract}

\section{INTRODUCTION}

The difficulty of producing high-purity chromium targets, which are widely used in industry for the deposition of coatings, is connected, first, with the difficult of melting chromium ingots pure in interstitials, and secondly, with the problem of thermoplastic treatment of ingots. These problems were solved in the Ukrainian National Academy of Sciences by the efforts of scientists of the Institutes for Problems of Material Science and Physics of Metals, and the results of this work are presented in this paper.

The choice of technique for the melting of metals and alloys is known to be conditioned by the physicochemical properties of their components. Producing high-purity compact chromium is fraught with difficulty due to its high chemical activity. For example, during vacuum melting of chemically active metals for which the equilibrium partial pressure of nitrogen and oxygen is considerably lower than can be achieved in vacuum furnaces, the content of gaseous impurities in the metal increases. The application of the plasma-arc melting technique achieves uniform heating of the liquid metal surface, but this technique is not always viable for the production of metals with a strong affinity for gaseous impurities owing to the heavy consumption of the expensive spectrally pure inert gases necessary for obtaining plasma. Induction melting of chemically active metals in ceramic crucibles leads to alloy contamination by the ceramic components. Induction melting in cold crucibles for obtaining ingots of refractory metals requires a highpower supply, high specific consumption of electric energy, etc. In some cases the application of combined techniques for metal heating is justified.

\section{PRODUCTION OF HIGH-PURITY CHROMIUM INGOTS}

We used the technique of induction-arc (IA) melting of chromium alloys in which melting is carried out simultaneously by means of induction and arc heating of the metal [1]. This melting technique is applied using two furnace variants enabling us to obtain ingots both by means of non-consumable (inert) electrodes and by remelting consumable electrodes (Fig.1). The ingot (1) is obtained by consecutive overlay of the metal in a water-cooled crystallizer consisting of vertical copper sections (4). The metal is heated by the arc between the electrode (2) and the melt (1), as well as by high-frequency currents with the help of the inductor (3). The voltage for the electric arc is applied to the holder (7) and furnace bottom (6) from the permanent current generator (PCG) through the ballast rheostat $\mathrm{RB}$. The inductor is powered by a highfrequency voltage from a lamp generator or from machine frequency converters. Both furnaces are vacuum, and melting can be done both in vacuo and in a protective or controlled atmosphere. When melting with a non-consumable electrode, the basic metal and the alloying additions in the necessary proportions enter from the weighing devices into the crystallizers while an ingot is growing.

The first furnace (Fig.1 a) in which the ingot and the crystallizer are placed inside a transparent quartz tube (5), has a comparatively small service volume and its consumption of inert gases for melting in a protective atmosphere is low. In such furnaces, melting is more advantageous in conditions when the atmosphere is 
composed of spectrally pure inert gases, but in this case the size of the ingots is limited by the diameter of the quartz tubes.

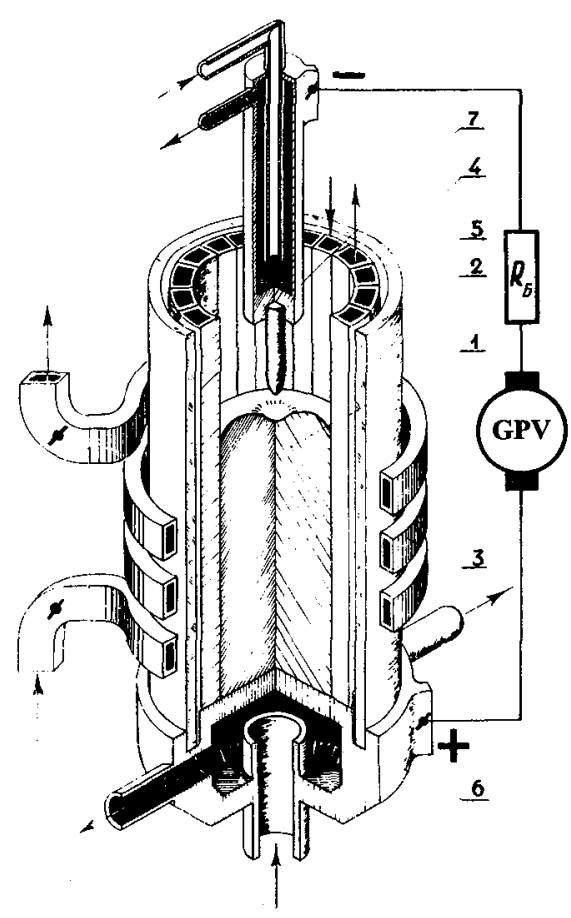

a)

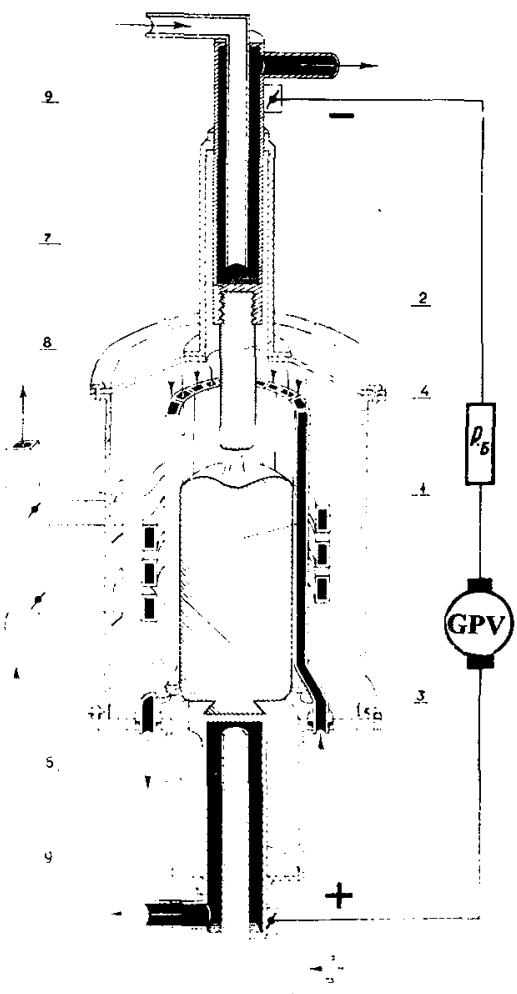

b)

Figure 1: Diagrams of furnaces with (a) consumable and (b) non-consumable electrodes used for producing high-purity chromium ingots.

The volume of service space in the second furnace (Fig.1b) is restricted only by the chamber (8) (the other designations are the same as in Fig.1a), and is much larger. This construction of furnace is suitable for obtaining large ingots which can be melted in vacuo or in a controlled atmosphere. Induction-arc melting can be performed both with non-consumable electrodes, using a free-flowing charge, and with consumable electrodes.

The IA melting technique in copper crystallizers has a number of technological peculiarities which make it more advantageous than other melting techniques. Let us point out the most important ones. The power supplied to the metal in the centre can be regulated through the arc, and for the peripheral areas this can be done through the inductor. It facilitates producing alloys with a wider temperature range of melting points and component evaporation. Due to the interaction of strong fields of permanent and high-frequency currents the liquid metal is subjected to intense electromagnetic stirring in the vertical direction, and as a result homogeneous and fine-grained ingots can be produced by one remelting. In furnaces with inductionarc heating of metal, any atmosphere (inert, reducing, oxidizing, nitrogen, vacuum etc.) with changing pressure within wide limits can be created. The efficiency of induction-arc melting is higher than in induction melting, making it possible, with the same power input, to melt ingots of larger diameter or alloys with higher melting temperatures. The absence of contact between the melt and the ceramics practically excludes contamination of the remelted metal.

The production of high-purity chromium ingots was performed with equipment which included the unit for induction-arc melting, with degassing chamber, apparatus for high-frequency heating of the metal, a permanent current supply and a system for the purification of inert gases. To increase the purity of 
commercial argon (such problems probably arise only in our conditions), we use an installation where argon is purified by calcium chips at $660^{\circ} \mathrm{C}$ and $\mathrm{Ti}-\mathrm{Zr}$ alloy at $750^{\circ} \mathrm{C}$.

With combined induction-arc heating it is possible to obtain ingots of high-purity, low-alloyed chromium, $70-120 \mathrm{~mm}$ in diameter, of sufficiently high quality (absence of porosity, unmelted areas or cracks). The total content of interstitials in the ingots did not exceed $0.02 \%$ in mass $(\mathrm{N}, \mathrm{O}$ within the limits $0.003-0.006$; $\mathrm{C}-0.003-0.01 \%$ in mass) and the ductile-brittle transition temperature was $18-24^{\circ} \mathrm{C}$. Since interstitial impurities lead to the essential embrittlement of chromium, it is sometimes effective to introduce some active components into the charge to bind them. E.g., introducing $0.2 \%$ in mass of lanthanum decreases the content of nitrogen and oxygen in solid solution to the values $10^{-3}$ and $10^{-5} \%$ in mass respectively, and reduces the ductile-brittle transition temperature to $-20^{\circ} \mathrm{C}$.

\section{PRODUCING CHROMIUM TARGETS}

The next stage in the process of producing targets was the elaboration of a scheme for the thermoplastic treatment of ingots. The conditions of deformation were chosen in accordance with the general principles worked out in $[2,3]$ and included hot deformation by forging, hot and warm deformation by rolling.

Using high temperatures for thermoplastic treatment of ingots could result in the saturation of the surface layers by interstitial impurities. For surface protection, steel sheaths were previously used, which made production very expensive. We used a hydrogen atmosphere for heating before rolling. The control of plate quality was performed by measuring the microhardness of the surface layers in the thickness of the plate. The absence of any noticeable increase in microhardness in sheets produced using a hydrogen protective atmosphere (in comparison with using steel sheaths) enables conclusions to be drawn about the possibility of the introduction of considerably more economical techniques for producing targets.

Thus, using the elaborated technique of hot plastic deformation (forging, rolling), plain targets of large size can be obtained. For example, an experimental target $750 \times 127 \times 10 \mathrm{~mm}$ in size was produced from lowalloyed chromium with additions of lanthanum (to $0.2 \%$ in mass).

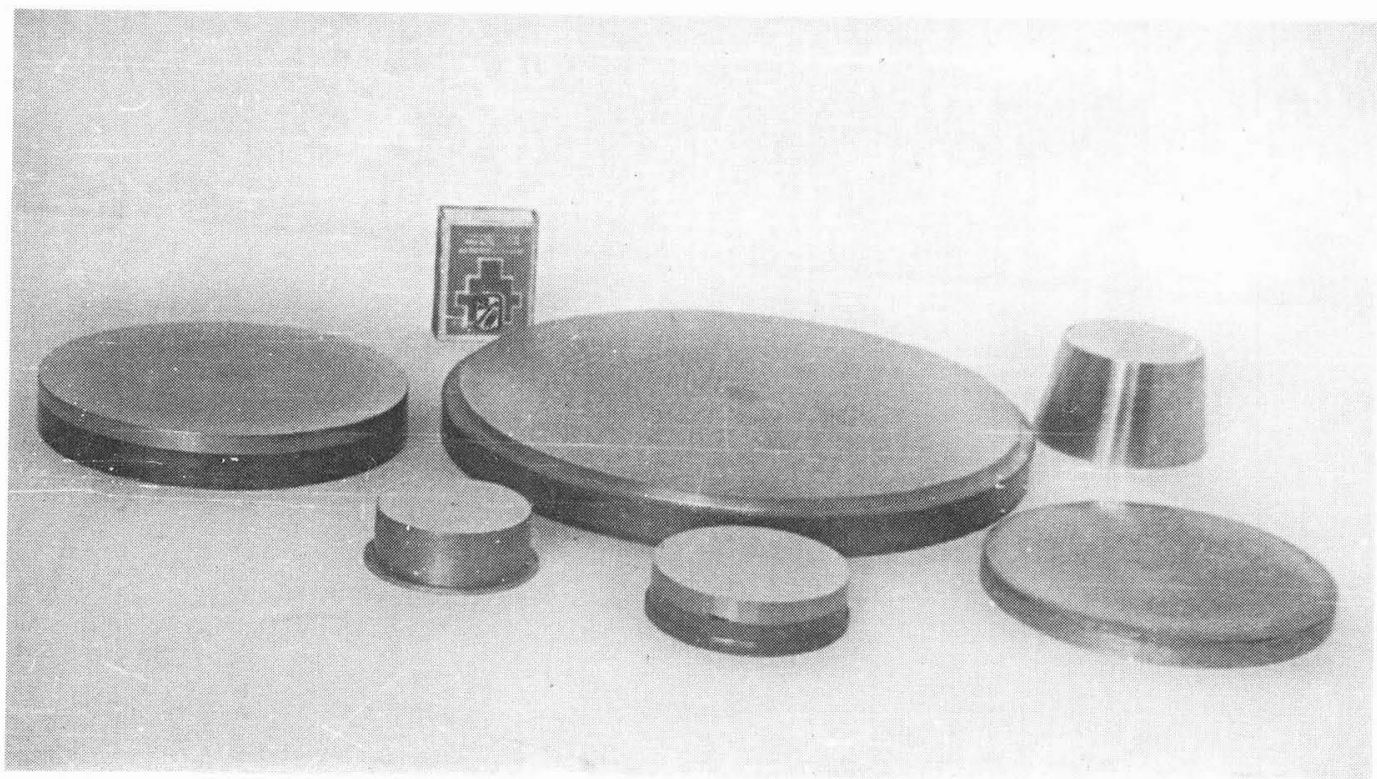

Figure 2 : Chromium targets and cathodes produced by the technique of electron-beam deposition of chromium on a copper substrate

Together with the Institute of Electro-Welding of the Ukrainian National Academy of Sciences, we tried to produce a chromium-copper bimetallic target of large size by the technique of electron-beam remelting [4] from high-purity chromium ingots. The evaporation of chromium by electron beam and its deposition on the copper substrate was performed in strictly defined conditions. One of the parameters defined for the 
process is the condensation rate. This strongly effects the chemical composition of sediments: with an increase of the evaporation rate, the content of oxygen in the sediments drops sharply, the content of nitrogen and carbon being unchanged.

Using pure charge materials, the proper rate of sediment growth and other parameters of the process established in the work, sediment densities not lower than $99.7 \%$ of theoretical levels were obtained.

With the use of the electron-beam technique for the evaporation of high-purity chromium ingots, a target $750 \times 150 \mathrm{~mm}$ in size was prepared (to reduce deformation of the substrate, the target was made in two parts), as well as targets and cathodes of smaller dimensions. Photographs of these are shown in Fig. 2.

Targets produced by the technique of ingot thermoplastic treatment are purer as to interstitials than targets prepared by the electron-beam technique. However, the proposed scheme of deformation for large-sized ingots made it possible to obtain a target $750 \times 127 \times 10 \mathrm{~mm}$ in size, only from low-alloyed chromium containing lanthanum (to $0.2 \%$ in mass).

\section{References}

[1] Rudoy A.P. and Fialkovskii R.V., Metallofizika 65 (1992) 104-106 (in Russian).

[2] Karetnikov I.A., Kosachev L.S., Milman Yu.V. et al., Doklady Akademii Nauk SSSR 263 (1982) 1366-1369.

[3] Trefilov V.I. and Milman Yu.V., "Physical basis of thermomechanical treatment of refractory metals", 12. Internat. Plansee Seminar'89, Reutte 8-12 May 1989, H.Bidstein and H.M.Ortner Eds. (Reutte, Tirol, Austria, 1989) pp.107-131.

[4] Movchan B.A., Grechanyuk N.I., Didikin G.G. et al., Thin Solid Films 111 (1984) 285-291. 